tion dynamics for the shallow shelf seas in the North Atlantic. Recent advances in geochemical techniques, including the "carbonate clumped isotope" method (Ghosh et al., 2006; Came et al., 2007), provide an excellent opportunity to reconstruct past ocean temperatures independent of $\delta^{18} \mathrm{O}_{\text {water }}$ or salinity using A. islandica and other suitable archives. Although A. islandica is restricted to the North Atlantic, other long-lived bivalves with annual banding, such as the geoduck clam (Panopea abrupta) from the Pacific, can also serve as reliable climate proxies (e.g., Strom et al., 2004), extending the geographical range in which ocean climate can be reconstructed using the methods described here.

\section{Summary}

A. islandica is a remarkable, yet underutilized, marine archive. Geochemical and master shell-growth records have the potential to greatly improve our understanding of key climate events/transitions, as well as ecosystem changes in the North Atlantic throughout much of the Holocene. Its great longevity, its fidelity as a proxy record, and its abundance and wide geographical distribution make $A$. islandica a key proxy archive for the North Atlantic region.

\section{Acknowledgements}

We thank the participants who attended the A. islandica workshop held at the Gregynog Conference Center, Wales in March 2008. This research is funded by European Climate of the Last Millennium (http://geography.swan.ac.uk/ millennium/) (Project no. 017008).

\section{Note}

Isotope data for Figure 3 is available from the NOAA paleoclimate database www.ncdc.noaa. gov/paleo/data.html

\section{References}

Marchitto, T.M., Jones, G.A., Goodfriend, G.A. and Weidman, C.R., 2000: Precise temporal correlation of Holocene mollusk shells using sclerochronology, Quaternary Research, 53: 236-246.

Schöne, B.R., Fiebig, J., Pfeiffer, M., Gleß, R., Hickson, J., Johnson, A., Dreyer, W. and Oschmann, W., 2005: Climate records from a bivalve Methuselah (Arctica islandica, Mollusca; Iceland), Palaeogeography, Palaeclimatology, Palaeoecology, 228: 130-148.

Scourse, J., Richardson, C., A., Forsythe, G., Harris, I., Heinemeier, J., Fraser, N., Briffa, K. and Jones, P., 2006: First cross-matched floating chronology from the marine fossil record: data from growth lines of the long-lived bivalve mollusc Arctica islandica, The Holocene, 16: 967-974.

Wanamaker A.D Ir Kreutz, KJ Schöne, BR Pettigrew N B Borns, H.W., Introne, D.S., Belknap, D., Maasch, K.A. and Feindel, S., 2008b: Coupled North Atlantic slope water forcing on Gulf of Maine temperatures over the past millennium, Climate Dynamics, doi:10.1007/s00382-007-0344-8.

Weidman, C.R., Jones, G.A. and Lohmann, K.C., 1994: The long-lived mollusk Arctica islandica: a new paleoceanographic tool for the reconstruction of bottom temperatures for the continental shelves of the northern North Atlantic Ocean, Journal of Geophysical Research-Oceans, 99: 18305-18314.

\title{
On the abyssal circulation in the Atlantic basin at the Last Glacial Maximum
}

\section{Olivier Marchal and William Curry}

Department of Geology and Geophysics; Woods Hole Oceanographic Institution, USA; omarchal@whoi.edu

Our understanding of oceanic variability on timescales longer than the time span of direct oceanographic measurements (about a century for most common measurements) relies on our capability to interpret the marine sediment record. Sediment observations have reached the point where hypotheses regarding oceanic conditions during specific time intervals of the geological past can be tested. An interval of preeminent interest is the Last Glacial Maximum (LGM, ca. 20 kyr BP), when large ice sheets occupied North America and northern Europe, and global sea level was reduced by more than $100 \mathrm{~m}$. Much effort has been devoted to estimating oceanic conditions during the LGM, in particular in the Atlantic basin. Hypotheses regarding the ocean circulation during the LGM are particularly relevant, given the postulated role of ocean circulation in climate change. Here we report on a test of the null hypothesis that observations from glacial sediments in the Atlantic basin are consistent with the modern circulation.

\section{A conventional view}

Among the most common measurements performed on glacial sediments are two isotopic ratios of calcite shells of benthic foraminifera (bottom-dwelling organisms): the oxygen isotopic ratio ${ }^{18} \mathrm{r}={ }^{18} \mathrm{O} /{ }^{16} \mathrm{O}$ and the carbon isotopic ratio ${ }^{13} \mathrm{r}={ }^{13} \mathrm{C} /{ }^{12} \mathrm{C}$. Both ratios are usually expressed as a relative

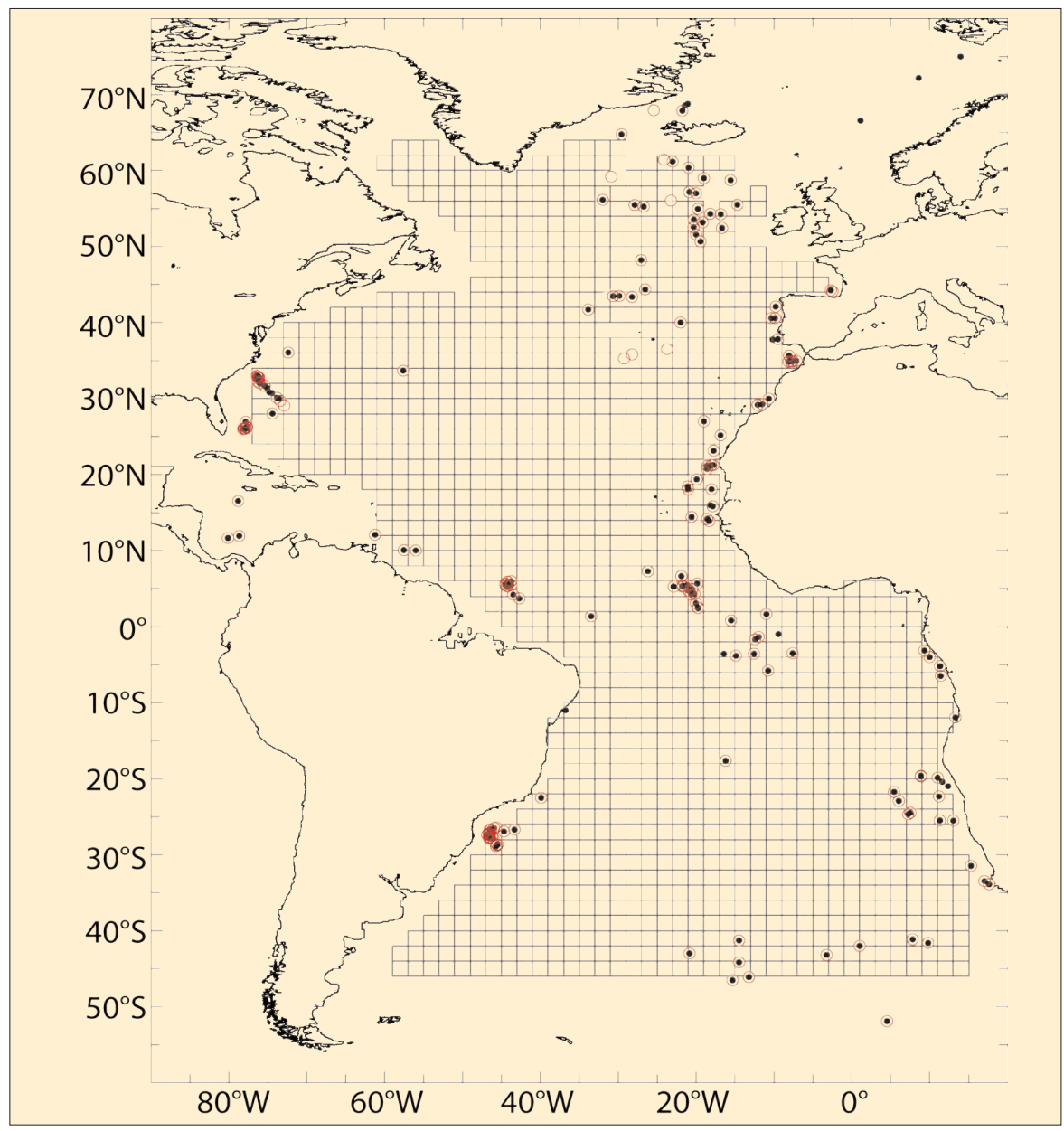

Figure 1: Location of the sediment cores considered in the compilation of benthic foraminiferal data for the Holocene (black dots; 198 measurements; defined as 0-3 kyr BP) and LGM (open red circles; ${ }^{18}$ O measurements; $18-21 \mathrm{kyr} B P$ ). Compilation includes data from both earlier syntheses and other sources. The benthic $\delta^{18} \mathrm{O}$ and $\delta^{13} \mathrm{C}$ measurements were conducted exclusively on the benthic taxa Cibicidoides and Planulina. Both post-glacial and glacial values are available at most core locations. Locations span the depth range 280-5105 m, with 50\% (80\%) of the cores from depths shallower than 2500 m (3750 m). Figure modified from Marchal and Curry, 2008. 
deviation from a standard ratio, i.e., $\delta^{18} \mathrm{O}$ $=\left({ }^{18} \mathrm{r} /{ }^{18} \mathrm{r}_{\mathrm{s}}-1\right) \times 1000$ and $\delta^{13} \mathrm{C}=\left({ }^{13} \mathrm{r} /{ }^{13} \mathrm{r}_{\mathrm{s}}-1\right)$ $x 1000$, where $\delta^{18} \mathrm{O}$ and $\delta^{13} \mathrm{C}$ units are per mil. Comparison of each ratio in benthic foraminifera from surface sediment with properties of ambient bottom water show that, in general, the benthic foraminiferal $\delta^{18} \mathrm{O}\left(\delta^{18} \mathrm{O}_{\mathrm{b}}\right)$ varies with the $\delta^{18} \mathrm{O}$ and temperature of the water (e.g., Lynch-Stieglitz et al., 1999), whereas the benthic foraminiferal $\delta^{13} \mathrm{C}\left(\delta^{13} C_{b}\right)$ varies with the $\delta^{13} \mathrm{C}$ of dissolved inorganic carbon $\left(\delta^{13} C_{D I C}\right)$ (e.g., Duplessy et al., 1984).

The observation that the benthic foraminiferal $\delta^{18} \mathrm{O}$ and $\delta^{13} \mathrm{C}$ generally reflect bottom water properties suggests that measurements of these ratios on fossil shells could constrain the same properties in the past. The dominant deepwater masses in the modern Atlantic-the North Atlantic Deep Water (NADW, with $\delta^{13} C_{\text {DIC }} \geq 1 \%$ o) and the Antarctic Bottom Water (AABW, $\delta^{13} C_{D I C} \approx 0.4 \%$ ) - are characterized by different $\delta^{13} C_{D I C}$ (Kroopnick, 1985). Thus, $\delta{ }^{13} C_{b}$ measurements from Atlantic sediments would also constrain the distribution of water masses of northern and southern origin. The most recent data compilation has been taken to imply the existence in the glacial Atlantic of a southern source water near $1000 \mathrm{~m}$ water depth (with low $\delta^{13} \mathrm{C}_{\mathrm{DIC}}$ ), a northern source water near $1500 \mathrm{~m}$ (high $\delta^{13} \mathrm{C}_{\mathrm{DIC}}$ ), and a southern source water below ca. $2000 \mathrm{~m}$ (low $\delta^{13} C_{D I C}$; Curry and Oppo, 2005). These inferences resonate with a conventional view that the glacial analoge of NADW was shallower and the glacial analoge of AABW was more voluminous in the Atlantic basin.

\section{The challenge}

The conventional notion that the distribution of NADW and AABW was different in the glacial Atlantic has not gone unchallenged. LeGrand and Wunsch (1995) argued that NADW and/or AABW, which are "formed" at high latitudes, could have entered the deep Atlantic with initial $\delta^{13} \mathrm{C}$ values that are different from today, which would then be recorded in the sediment. They showed that different assumptions about these initial values lead to significantly different depictions of these water masses in the glacial Atlantic. Whereas some of the values they assume may not be consistent with recent observations, the effect of varying initial composition on inferences about water mass distribution can be significant (e.g., Rutberg and Peacock, 2006). LeGrand and Wunsch used an inverse method to conclude that benthic $\delta^{18} \mathrm{O}$ and $\delta^{13} \mathrm{C}$ data for the LGM are consistent with any flux of NADW in the North

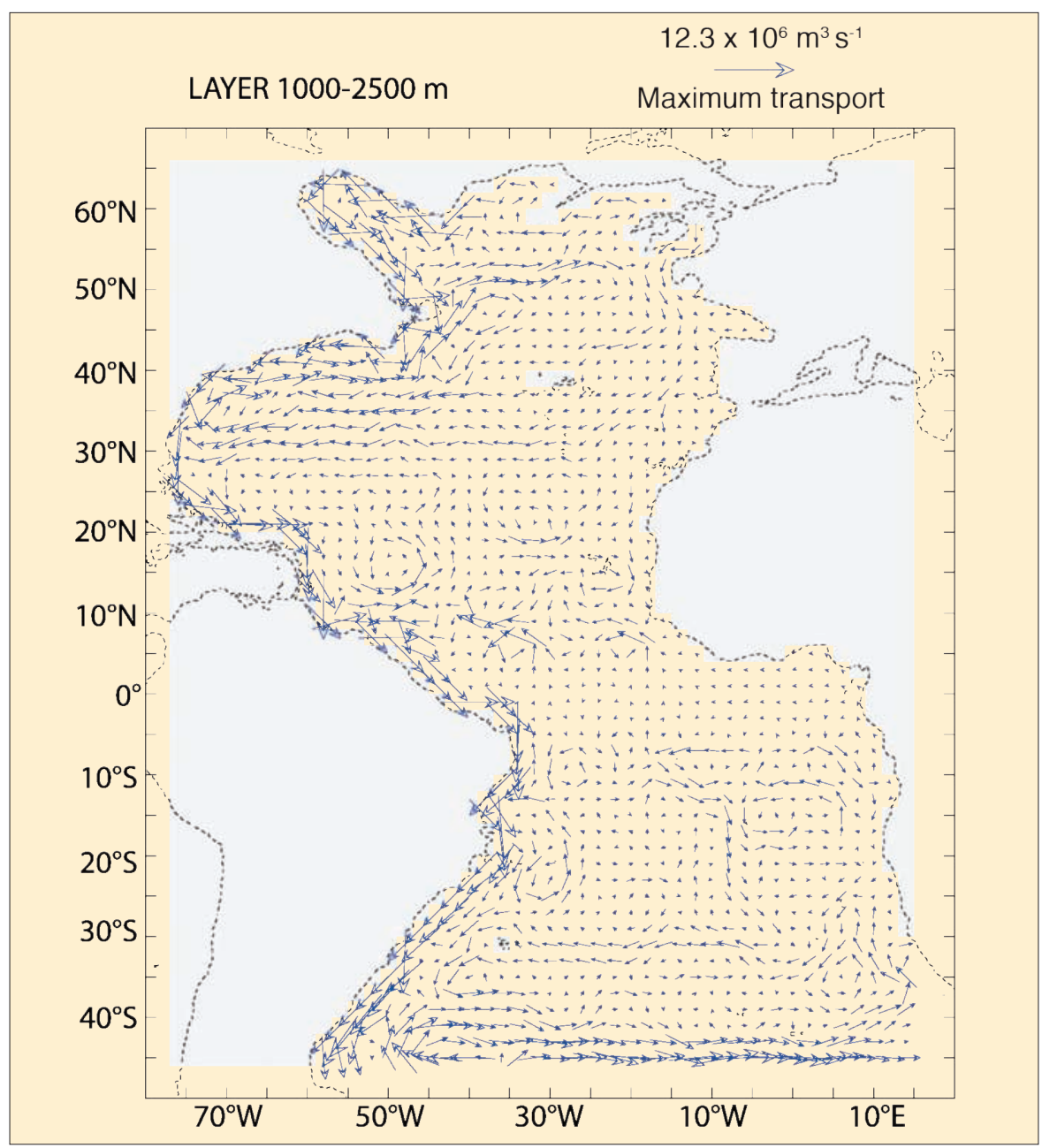

Figure 2: Distribution of the horizontal water transport (in units $10^{6} \mathrm{~m}^{3} \mathrm{~s}^{-1}$ ) between 1000-2500 $\mathrm{m}$ in the modern Atlantic, estimated by combining hydrographic data and a circulation model. Maximum transport is $12.3 \times 10^{6} \mathrm{~m}^{3}$ $5^{-1}$. Dashed line and white areas show the coastline and model topography, respectively. The hydrographic data used are (i) climatologies of temperature and salinity; (ii) observational estimates of volume transport of NADW, AABW, and Mediterranean Outflow Water at specific locations; and (iii) observational estimates of the zonally integrated meridional flow at different latitudes based on transatlantic sections. The circulation model is a non-linear, geostrophic, finite-difference model. Horizontal flow is dominated by southward current along the western boundary (NADW) and several coherent structures in the interior. Figure modified from Marchal and Curry (2008).

Atlantic. None of these data, they argued, can provide constraints on the rates of water motion.

\section{New insights}

Recently, we have used an updated compilation of benthic $\delta^{18} \mathrm{O}$ and $\delta^{13} \mathrm{C}$ data from Atlantic sediments (Marchal and Curry, 2008; Fig. 1) to provide a new test of the null hypothesis that these data are consistent with the modern circulation in the abyssal basin. First, an inverse method was applied to produce an estimate of the abyssal circulation in the modern Atlantic (Fig. 2). This circulation estimate served as a reference state for the null hypothesis that the sediment data are compatible with the modern flow. Second, the inverse method was used to combine, with the modern flow, estimates of two different water properties derived from the sediment data: The $\delta^{18} \mathrm{O}$ of equilibrium calcite or $\delta^{18} \mathrm{O}_{c}$ (derived from $\delta^{18} \mathrm{O}_{b}$ ) - which is a linear combination of water $\delta^{18} \mathrm{O}$ and temperature-and $\delta^{13} C_{D I C}$ (derived from $\left.\delta^{13} C_{b}\right)$.
We found that relatively small adjustments in the $\delta^{18} \mathrm{O}_{c}$ distributions for the Holocene and LGM are necessary to bring these distributions into consistency with the modern circulation. On the other hand, the adjustments in the $\delta^{13} \mathrm{C}_{\mathrm{DIC}}$ distributions to comply with the modern flow are larger. Assuming that (i) the $\delta^{13} C_{D I C}$ estimates have an uncertainty of $0.1 \%$ and (ii) deep water $\delta^{13} C_{D I C}$ is governed primarily by a balance between the effects of water advection and organic matter remineralization (organic matter has a low ${ }^{13} \mathrm{C} /{ }^{12} \mathrm{C}$, so its oxidation tends to depress the $\delta^{13} \mathrm{C}$ of ambient DIC), the number of $\delta^{13} C_{D I C}$ values closest to core locations that are adjusted by more than 2 standard deviations is 8 for the Holocene and 25 for the LGM (Fig. 3). These numbers correspond, respectively, to $7 \%$ and $21 \%$ of the total number of $\delta^{13} C_{D I C}$ values at grid points closest to core locations (note that the number of these points is less than the number of core locations, since more than one core location may have the same grid point as the closest point). Thus, under the assumptions 


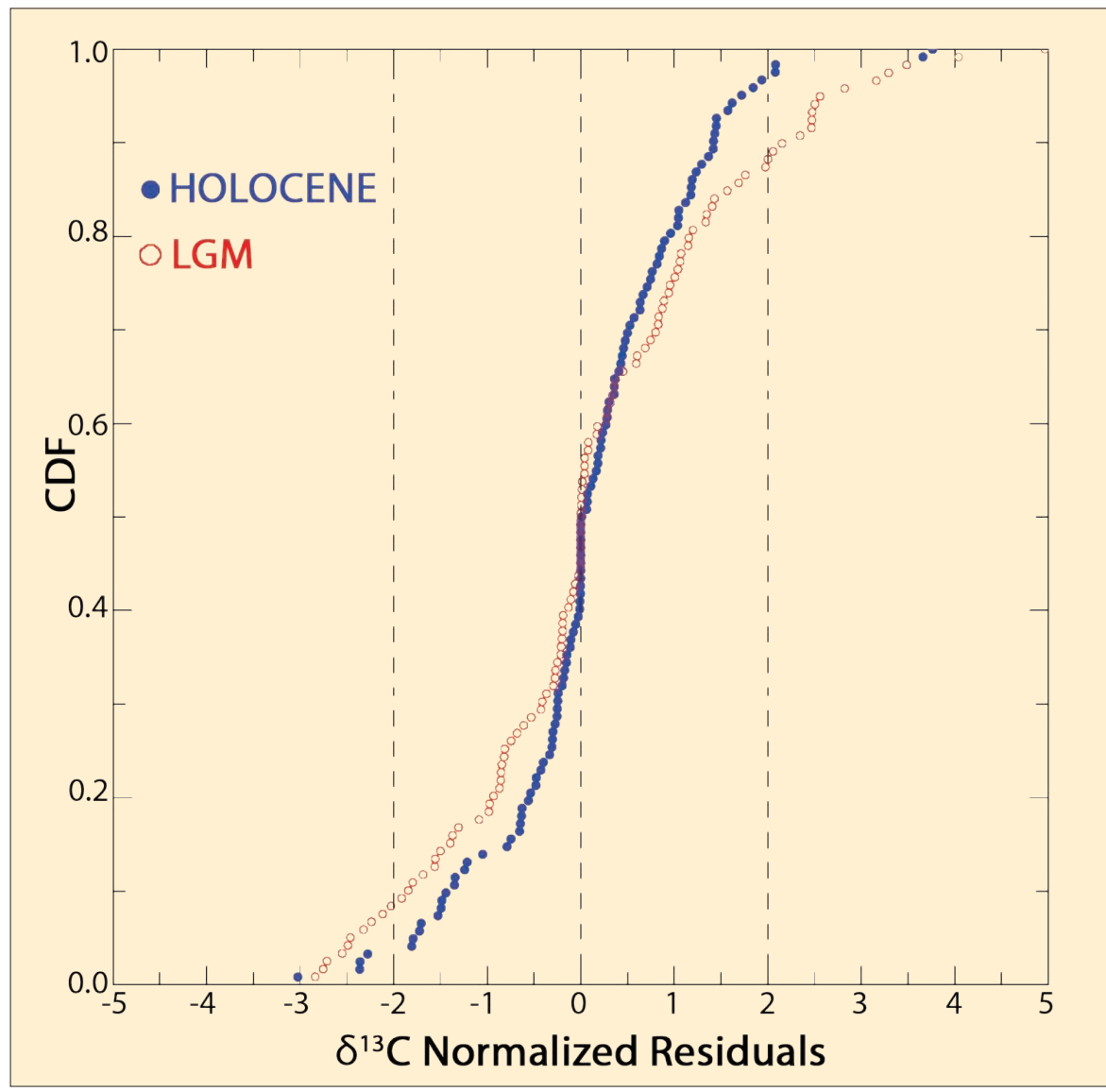

Figure 3: Cumulative distribution function (CDF) of the $\delta^{13} \mathrm{C}$ normalized residuals at the grid points closest to core locations. The $\delta^{13} C_{D, C}$ normalized residual is the difference between the posterior value of $\delta^{13} C_{D I C}$ (i.e., the value after inversion or "demanded" by the modern circulation) and the prior value of $\delta^{13} C_{D, c}$ (i.e., the value before inversion or "demanded" by $\delta^{13} \mathrm{C}_{b}$ data), divided by the standard deviation in the prior value. Thus, a normalized residual larger than 2 in absolute magnitude signifies that the prior value of $\delta^{13} C_{\text {prc }}$ needs to be adjusted by more than 2 standard deviations in order to be consistent with the modern circulation. A large fraction of such residuals would suggest that the benthic $\delta^{13} \mathrm{C}$ data are not consistent with the modern circulation. Figure modified from Marchal and Curry, 2008

stated above, compatibility of the glacial $\delta^{13} \mathrm{C}_{\mathrm{b}}$ data with the modern circulation can be rejected with a certain confidence.

Note that the uncertainty in the glacial $\delta^{13} C_{D I C}$ estimates should account for the errors both in sediment core chronology and in how representative $\delta^{13} C_{b}$ measurements are of glacial $\delta^{13} C_{D I C}$. Importantly, it is the statistical dispersion of the difference between $\delta^{13} C_{b}$ and $\delta^{13} C_{D I C}$ that is relevant for the interpretation of $\delta^{13} C_{b}$ data in our analysis, not the difference itself. Whereas the errors arising from chronology are not readily quantifiable, the
We think that our work significantly extends earlier applications of inverse methods to paleoceanography (LeGrand and
Wunsch, 1995; Winguth et al., 2000; Gebbie and Huybers, 2006; Huybers et al., 2007). It also offers several prospects. The geographic locations where the largest adjustments in $\delta^{13} C_{\text {DIC }}$ estimates are needed to reach consistency with the modern circulation have been identified. These locations provide guidance as to where additional measurements (in sediment as well as in water) should be conducted to better constrain the uncertainties in the glacial $\delta^{13} C_{D I C}$ estimates and hence increase the power of the test. Furthermore, our work has considered only two types of paleoceanographic observation. Other types of observation have been presented as constraints on deep ocean circulation in the geological past (for a recent review see Lynch-Stieglitz et al., 2007). Although the number of such observations is much less than the number of $\delta^{18} \mathrm{O}_{b}$ and $\delta^{13} \mathrm{C}_{b}$ data, they should be considered if an exhaustive analysis of paleoceanographic observations for the glacial Atlantic is to be attempted.

\section{Note}

Data are available from NOAA National Geophysical Data Center www.ngdc.noaa.gov/

\section{References}

Curry, W.B. and Oppo, D, 2005: Glacial water mass geometry and the distribution of $\delta^{13} \mathrm{C}$ of $\Sigma \mathrm{CO}$ in the Western Atlantic Ocean, Paleoceanography, 20: PA1017, doi:10.1029/2004PA0011021.

Duplessy, J.-C., Shackleton, N.J., Matthews, R.K., Prell, W., Ruddiman, W.F., Caralp, M. and Hendy, C.H., 1984: ${ }^{13} \mathrm{C}$ record of benthic foraminifera in the last interglacial ocean: Implications for the carbon cycle and the global deep water circulation, Quaternary Research, 21: 225-243.

Kroopnick, P.M., 1985: The distribution of ${ }^{13} \mathrm{C}$ of TCO in the world oceans, Deep-Sea Research, 32: 57-84.

LeGrand, P. and Wunsch, C., 1995: Constraints from paleotracer data on the North Atlantic circulation during the last glacial maximum, Paleoceanography, 10: 1011-1045.

Marchal, O. and Curry, W. B., 2008: On the abyssal circulation in the glacial Atlantic, Journal of Physical Oceanography, DOl: 10.1175/2008JP03895.1

\section{For full references please consult:}

www.pages-igbp.org/products/newsletters/ref2008_3.html

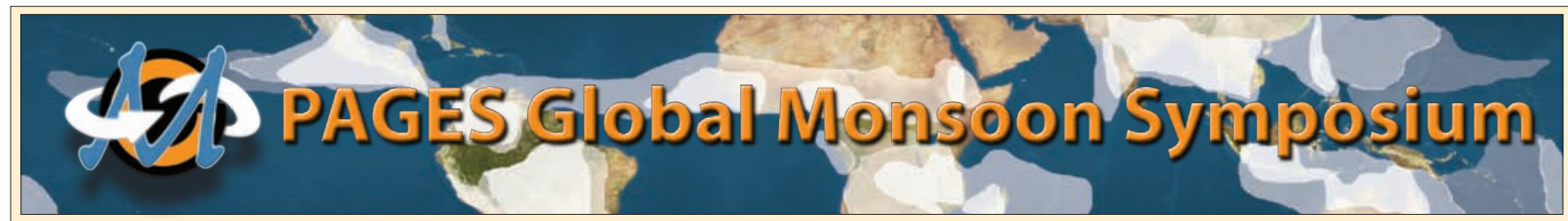

\section{9 - 31 October 2008, Shanghai, China}

The symposium will bring together paleo- and modern climatologists, data-producers and modelers working on monsoon variations in different regions. The objectives are to compare monsoon records and simulations from all major regional monsoon systems, to find out their similarities and differences across various timescales, and to unravel the mechanisms causing variations in the global monsoon system and of regional deviations from the global trend.

Early registration and abstract submission deadline: 31 August 2008

Visit www.pages-igbp.org/science/monsoon/ for more information 